\title{
SÍNTESE ORGÂNICA LIMPA
}

\author{
Antonio Manzolillo Sanseverino* \\ Instituto de Química - Departamento de Química Orgânica - Universidade Federal do Rio de Janeiro - 21949-900 - Rio de Janeiro - RJ
}

Recebido em 19/11/98; aceito em 15/6/99

\begin{abstract}
CLEAN ORGANIC SYNTHESIS. An introduction to the fundamental concepts and main aspects of organic clean synthesis is given, and relevant industrial examples which have implemented the philosophy of cleaner synthesis are also presented. Recent trends in organic synthesis which are environmentally friendly are also discussed.
\end{abstract}

Keywords: clean organic synthesis; atom economy; green chemistry.

\section{INTRODUÇÃO}

A questão ecológica ou uma maior preocupação com o meio ambiente surgiu no final da década de 1960 e tomou forte impulso nos anos 70. Atualmente, este é um assunto de grande relevância e enorme repercussão na sociedade. Para a indústria química este tema pode definir a sobrevivência ou não de algumas empresas ou atividades ligadas à química ${ }^{1}$. A implantação em uma escala mundial da norma iso-14.000 (gerência para o meio-ambiente) já é uma realidade e uma exigência importante para diversas empresas ${ }^{2}$.

A ONU (Organização das Nações Unidas) que possui programas na área de meio ambiente e desenvolvimento industrial que visam a redução da geração de resíduos industriais já teria afirmado que poluição seria uma demonstração de ineficiência dos processos produtivos, ou seja, o resíduo seria, antes de mais nada, matéria-prima que estaria sendo jogada fora ${ }^{1}$.

Terminologias como tecnologia limpa ${ }^{3}$, processo limpo ${ }^{1}$, síntese limpa ${ }^{3}$ e química verde ${ }^{4}$, tem se tornado muito frequentes na literatura nos últimos anos, sendo que já existem revistas especializadas nestes assuntos, como Journal of Cleaner Production $^{3}$ e o recém lançado Green Chemistry Journal ${ }^{4 \mathrm{~b}}$.

Existe uma forte tendência para um melhor aproveitamento de recursos naturais e um maior cuidado com o meio ambiente, que pode ser percebida a partir de certas mudanças citadas por Torres ${ }^{1}$ e que vem ocorrendo ao longo dos anos:

- Os carros de 25 anos atrás eram cem vezes mais poluentes que os atuais, que são melhores e mais econômicos.

- Novas geladeiras americanas consomem $70 \%$ menos eletricidade e não usam gás CFC.

- O novo Boeing 777 queima apenas a metade do combustível que os jatos comerciais da década de 80 .

- Em 1970 eram necessários 74 quilos de metal para produzir 1.000 latas de refrigerante. Hoje bastam 16 quilos.

Um outro fato interessante nesta linha é o relatório anual sobre emissão de substâncias químicas para o meio ambiente lançado pela Agência de Proteção Ambiental nos Estados Unidos, mostrando que o volume total de emissões neste país continua caindo, como é constatado para algumas substâncias na Tabela $1^{5}$.

Desta forma, o objetivo deste trabalho é apresentar uma introdução aos conceitos e aspectos mais importantes que contribuem para uma síntese orgânica mais limpa e eficiente para o meio ambiente, além de relatar alguns exemplos na indústria química que evidenciam a aplicação desta filosofia de síntese limpa.

*E-mail: amsansev@iq.ufrj.br
Tabela 1. Redução nas emissões de certos produtos químicos nos Estados Unidos.

\begin{tabular}{lccc}
\hline $\begin{array}{l}\text { SUBSTÂNCIA } \\
(\text { Milhões de lb) }\end{array}$ & $\begin{array}{c}\text { ANO } \\
1987\end{array}$ & $\begin{array}{c}\text { ANO } \\
1996\end{array}$ & $\begin{array}{c}\text { Diferença } \\
(\%)\end{array}$ \\
\hline HCl & 657 & 65 & -90 \\
Metanol & 420 & 241 & -43 \\
Diclorometano & 152 & 54 & -64 \\
Amônia & 444 & 193 & -57 \\
Tolueno & 345 & 127 & -63 \\
Compostos com Cobre & 179 & 57 & -68 \\
Dissulfeto de Carbono & 137 & 73 & -47 \\
\hline
\end{tabular}

\section{SÍNTESE LIMPA}

Atualmente, a indústria química tem procurado adotar uma postura de redução, prevenção ou eliminação dos resíduos de processo. A reutilização dos resíduos também faz parte desta postura. A filosofia mais moderna procura diminuir a poluição através da minimização dos resíduos, ao invés de tratar o efluente gerado procura-se evitar sua geração ${ }^{1,3}$. Tradicionalmente, ao final do processo encaminhava-se o resíduo para a unidade de tratamento de efluentes, que buscava ajustar as cargas emitidas aos parâmetros estabelecidos para os lançamentos ${ }^{1,3}$.

Uma escala de prioridades para o problema da geração de resíduos adotada por esta filosofia mais moderna teria os seguintes passos em ordem decrescente de importância, como abordado por Torres ${ }^{1}$ :

1 - Evitar a geração

2 - Minimizar a geração

3 - Reciclar o resíduo

4 - Reutilizar o resíduo

5 - Dar ao resíduo tratamento químico, físico, biológico ou incineração

6 - Dispor o resíduo de forma adequada no solo

No entanto, o que ocorre na prática é a inversão desta escala de prioridades, e é contra esta situação que a sociedade deve lutar para um melhor aproveitamento de recursos naturais e uma efetiva não agressão ao meio ambiente ${ }^{1}$.

Um processo sintético eficiente deve, em linhas gerais, possuir as seguintes características ${ }^{3,6}$ :

- possuir seletividade

brevidade (menor número possível de etapas)

- permitir recuperação de solventes e matéria-prima 
- alto rendimento e pureza do produto desejado

- minimizar efluentes aquosos ou de outros tipos

- não utilizar solvente sempre que possível

- usar solventes menos tóxicos e não inflamáveis

usar água como solvente

evitar misturas de solventes

utilizar solventes e reagentes baratos e disponíveis

não agredir o meio ambiente

possuir uma eficiência de volume ("throughtput") aceitável, isto é, o número de $\mathrm{Kg}$ de produto obtido por litro de volume do reator por hora.

- ser catalítico sempre que possível

Então, uma síntese orgânica ideal não deve apenas possuir um bom rendimento e pureza do produto, sendo necessário levar em conta estes outros fatores, sendo que modernamente a questão ambiental e de reaproveitamento de rejeitos influencia tremendamente na eficiência do processo.

A síntese de complicadas moléculas biologicamente ativas na indústria farmacêutica e agroquímica, geralmente, envolve diversas etapas com rendimentos totais tão baixos quanto 10 $\%^{3}$ (embora um rendimento final de $10 \%$ possa ser considerado muito alto dependendo do número de etapas e da complexidade estrutural do produto formado). E é claro que há grande geração de rejeitos e subprodutos nestas sínteses. Uma questão importante para avaliar a poluição ambiental gerada por um processo é a razão da quantidade em $\mathrm{Kg}$ de subprodutos (orgânicos e inorgânicos) por $\mathrm{Kg}$ de produto $^{3,7}$. A tabela 2 mostra setores da indústria química e a quantidade de subprodutos por produto gerado, segundo avaliação de Sheldon ${ }^{7}$.

$\mathrm{O}$ cloreto de alumínio $\left(\mathrm{AlCl}_{3}\right)$ é um material muito utilizado em síntese orgânica, como por exemplo nas reações de alquilação e acilação de Friedel-Crafts. No entanto, o uso do $\mathrm{AlCl}_{3}$ como catalisador nestas reações gera grande quantidade de rejeitos com alumínio, e apesar de muito esforço para substituir este catalisador por outros mais amenos para o meio ambiente (como zeólitas), a demanda mundial por $\mathrm{AlCl}_{3}$ é ainda de 75.000 toneladas por ano $^{3}$, sendo grande parte destinada para catalisadores de Friedel-Crafts.

A substituição de reagentes ou catalisadores por outros menos nocivos para o meio ambiente também faz parte da filosofia de síntese limpa, e quando é possível até mudar a substância química produzida para outra que tenha a mesma finalidade mas seja de manufatura mais limpa ${ }^{3}$. Um exemplo importante desta idéia é a substituição do fosgênio $\left(\mathrm{COCl}_{2}\right)$, um gás extremamente tóxico e corrosivo, por outros compostos menos agressivos, sendo que o fosgênio é usado em diversas sínteses como na produção de carbamatos, carbonatos orgânicos e polímeros, tendo uma produção mundial estimada em 1,2 megatoneladas por ano ${ }^{8}$. Transporte e armazenagem deste composto são também problemas críticos na indústria. Este intermediário é preparado pela reação de monóxido de carbono com cloro (Equação 1).

$$
\mathrm{CO}+\mathrm{Cl}_{2} \underset{1250 \mathrm{C}}{\stackrel{\text { carbono ativo }}{\longrightarrow}} \mathrm{COCI}_{2}
$$

Equação 1. Obtenção do fosgênio.
Um novo processo industrial para a produção de dimetilcarbonato (DMC) teria sido desenvolvido pela companhia italiana Enichem, onde ocorreu a substituição do fosgênio por monóxido de carbono e onde plantas operando com uma capacidade de 12.000 t/ano estariam usando este processo $^{8}$ (Esquema 1). O DMC tem sido utilizado como uma alternativa mais amena para o meio ambiente em processos de metilação, carbonilação e carboximetilação que outros agentes tradicionalmente usados para este fim, como $\mathrm{COCl}_{2}, \mathrm{CH}_{3} \mathrm{OC}(\mathrm{O}) \mathrm{Cl}$ (cloroformiato de metila), $\left(\mathrm{CH}_{3}\right)_{2} \mathrm{SO}_{4}$ (dimetilsulfato) ou haletos de metila (MeX), além de poder ser usado como aditivo na gasolina para diminuir emissões e aumentar a combustão. Um outro substituto interessante é o $\mathrm{CO}_{2}$, que é barato, não tóxico, plenamente disponível e tem sido muito estudado para substituir o fosgênio ${ }^{8}$.

Processo Convencional:

$$
\begin{aligned}
& \left.\mathrm{COCl}_{2}+2 \mathrm{MeOH} \longrightarrow \mathrm{CH}_{3} \mathrm{OC(O}\right) \mathrm{OCH}_{3}+2 \mathrm{HCl} \\
& \text { (DMC) }
\end{aligned}
$$

Processo novo:

$$
2 \mathrm{MeOH}+\mathrm{CO}+\mathrm{O}_{2} \frac{\mathrm{CuCl}^{2} \mathrm{CuCl}_{2}}{\frac{120-130 \mathrm{OC}}{20-30 \mathrm{~atm}}}-\mathrm{CH}_{3} \mathrm{OC}(\mathrm{O}) \mathrm{OCH}_{3}+\mathrm{H}_{2} \mathrm{O}
$$

Esquema 1. Substituição do fosgênio por monóxido de carbono.

Pesquisa no sentido de alternativas mais adequadas para o meio ambiente em relação ao uso de agentes oxidantes baseados em crômio e manganês, que geram efluentes metálicos tóxicos, também tem sido feitas devido a pressões ambientais reguladoras da emissão destes metais ${ }^{3}$.

Uma outra característica importante para a filosofia de síntese limpa e que também é uma recente tendência em síntese orgânica é a chamada economia de átomos?

\section{ECONOMIA ATÔMICA}

O famoso químico Barry M. Trost em um artigo interessantíssimo para a revista Nature em 1991 abordou a questão de economia atômica, que é uma procura para uma maior eficiência sintética ${ }^{9}$. Mas o que vem a ser esta tão falada economia atômica? Quando se analisa a eficiência de uma síntese, uma característica importante é geralmente negligenciada, isto é, quanto dos reagentes terminam incorporados nos produtos, que foi definido por Trost como sendo economia atômica. Considere, por exemplo, a inserção de metileno com o brometo de metil-trifenil-fosfônio (reação de Wittig ${ }^{10}$ ) onde uma massa de apenas 14 em 357 é transferida. A transferência desta quantidade de massa atômica não é econômica ou eficiente, mas a reação resolve um importante problema sintético que não seria resolvido por outra maneira ${ }^{9}$ (Esquema 2).

Segundo Trost a reação ideal seria aquela onde toda a massa dos reagentes fosse incorporada no produto. A vantagem desta reação seria menor geração de resíduos e uma utilização mais efetiva de matérias-primas limitadas. Algumas destas

Tabela 2. Setores industriais e razão de subprodutos gerados por produto obtido.

\begin{tabular}{lcl}
\hline $\begin{array}{l}\text { Setor } \\
\text { Industrial }\end{array}$ & $\begin{array}{c}\text { Tonelagem } \\
\text { de Produto }\end{array}$ & $\begin{array}{l}\text { Razão Kg Subprodutos / } \\
\text { Kg de Produto }\end{array}$ \\
\hline Refinamento do Petróleo & $10^{6}-10^{8}$ & $\sim 0,1$ \\
Indústria Química de Base & & $<1-5$ \\
("Bulk Chemicals") & $10^{4}-10^{6}$ & $5-50$ \\
Química Fina & $10^{2}-10^{4}$ & $25-100+$ \\
Farmacêutica & $10^{1}-10^{3}$ & \\
\hline
\end{tabular}




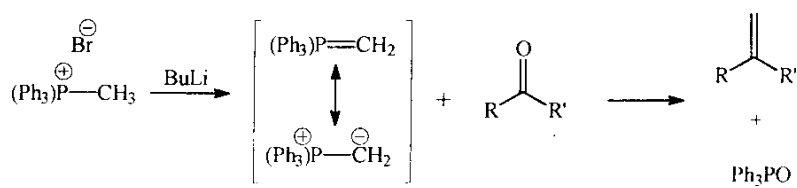

Esquema 2. Reação de Wittig.

reações já existem no repertório de métodos sintéticos do químico orgânico, como por exemplo reações de Diels-Alder. O assunto também foi abordado de forma semelhante por Sheldon $^{7}$. Recentemente, Trost recebeu nos Estados Unidos um importante prêmio de Química Verde pelo desenvolvimento do conceito de economia atômica ${ }^{11}$.

A produção industrial de $t$-butil-amina é feita de forma convencional pela reação de Ritter (Esquema 3), e ao analisar-se as reações verifica-se uma utilização atômica de $61 \%$ (calculada dividindo-se a massa molecular do produto desejado pela soma de todos os "produtos") $)^{3,7}$.

$$
\begin{aligned}
& \left(\mathrm{CH}_{3}\right)_{2} \mathrm{C}=\mathrm{CH}_{2} \stackrel{\mathrm{HCN} \cdot \mathrm{H}_{3} \mathrm{O}^{9}}{\longrightarrow}\left(\mathrm{CH}_{3}\right)_{3} \mathrm{CNHCHO} \stackrel{\mathrm{H}_{3} \mathrm{O}^{\ominus}}{\longrightarrow}\left(\mathrm{CH}_{3}\right)_{3} \mathrm{CNH}_{2}+\mathrm{HCOOH} \\
& \begin{array}{l}
73+46=119 \\
(73 / 119) \times 100-61 \%
\end{array} \quad 73 \mathrm{gjmol} \quad 46 \mathrm{~g} / \mathrm{mol}
\end{aligned}
$$

Esquema 3. Produção convencional de t-butil-amina.

A BASF teria desenvolvido uma síntese orgânica mais limpa para a produção da $t$-butil-amina que possui $100 \%$ de utilização atômica, através de catálise por zeólita ${ }^{3}$ :

$$
\left(\mathrm{CH}_{3}\right)_{2} \mathrm{C}=\mathrm{CH}_{2}+\mathrm{NH}_{3} \stackrel{\text { zeólita }}{\longrightarrow}\left(\mathrm{CH}_{3}\right)_{3} \mathrm{CNH}_{2}
$$

Equação 2. Novo processo da BASF para a síntese da $\mathrm{t}$-butil-amina.

Além disso, o processo convencional sofria com a formação de sais no processo de isolamento do produto, que é um problema importantíssimo para o tratamento e descarte de resíduos industriais. Então, este processo da BASF ilustra muito bem os conceitos de eficiência atômica e síntese limpa. A utilização de catalisadores ácidos sólidos como zeólitas e outros é uma tecnologia promissora para o futuro, sendo que já existem processos comerciais e plantas piloto utilizando estes catalisadores, onde algumas vantagens sobre os tradicionais catalisadores ácidos homogêneos seriam menor geração de rejeitos, maior seletividade e o fato de não serem corrosivos ${ }^{12}$

Embora estes conceitos sejam muito novos, eles estão gradualmente sendo incorporados na indústria devido a pressões econômicas como necessidade de baixar custos de matériasprimas e energia, e também por pressões governamentais ou de grupos ambientalistas.

Um outro exemplo de aplicação dos conceitos de síntese limpa é o processo industrial desenvolvido para a síntese do analgésico ibuprofeno da Hoechst-Celanese a partir do isobutilbenzeno que consiste em três etapas, duas das quais catalíticas, e uma utilização atômica de $77 \%$, sendo um considerável avanço em relação à rota clássica da companhia Boots (que descobriu o ibuprofeno) que possui 6 etapas e uma pobre utilização atômica, bem como uma bem maior geração de sais (Esquema $4)^{7}$. Além disso, duas etapas da nova síntese do ibuprofeno não usam solvente. A venda anual deste medicamento é de cerca de US\$ 1.400 milhões e um volume de produção de 8.000 t/ano ${ }^{7}$. Uma planta operando no Texas realiza esta síntese em uma escala de 4.000 toneladas por ano ${ }^{13}$. Esta síntese também ganhou um prêmio de Química Verde nos Estados Unidos ${ }^{14}$.

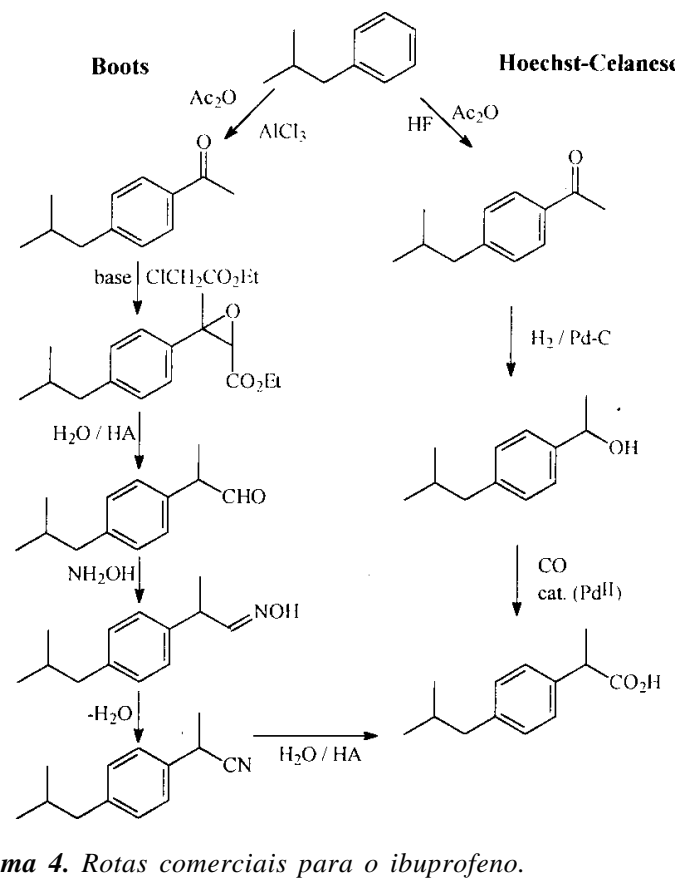

SOLVENTES

Solventes possuem um papel importantíssimo na indústria. Cerca de 50 ou mais solventes estão disponíveis no mercado em grande escala, para uma enorme variedade de aplicações, tais como: processos de extração, matéria-prima para fabricar outros produtos químicos, propelentes em aerossóis, na indústria de tintas, em cosméticos, etc ${ }^{15}$.

Recuperação e descarte de solventes são tópicos fundamentais que possuem relevantes aspectos econômicos e ambientais ${ }^{15}$. Deve-se observar que a não recuperação de solventes acarreta, geralmente, um maior custo em termos de tratamento de efluentes e um desperdício de um material que poderia ser reaproveitado. A toxidade, inflamabilidade e os limites permitidos para a exposição de um trabalhador para um determinado solvente são também aspectos fundamentais e que são sujeitos a grande pressão pelos órgãos reguladores destas questões e da própria sociedade. Além do manuseio, a estocagem e transporte de solventes também são problemas adicionais. A tabela 3 mostra os limites de exposição permitidos para alguns solventes segundo dois órgãos americanos ${ }^{16 a, b, c}$ e pela legislação brasilei$\mathrm{ra}^{17}$ (NR-15). O novo limite de tolerância para $8 \mathrm{~h}$ de trabalho recentemente adotado pela OSHA para o diclorometano (de 500 para $25 \mathrm{ppm}$ ) tem sido alvo de grande discussão entre este órgão e as indústrias produtoras ou usuárias deste solvente, que acreditam ser muito difícil atingir este limite e que poderia haver falências no setor se o limite fosse realmente implementado ${ }^{16 \mathrm{~d}}$.

\section{ÁGUA COMO SOLVENTE PARA REAÇÕES ORGÂNICAS}

A água é um solvente barato, normalmente disponível, não inflamável, não tóxico e que não polui o meio ambiente. Segundo King e colaboradores é impressionante como a água é pouco usada como solvente de reações orgânicas, a luz da variedade e eficiência de reações em meio aquoso que ocorrem na natureza ${ }^{18}$. Isto ocorre em parte devido a baixa solubilidade de muitos compostos orgânicos e a incompatibilidade de intermediários, reagentes e catalisadores com a água, e também devido a competição do processo desejado com hidrólise ou de reações com participação da água ${ }^{18,19}$. King e colaboradores, neste trabalho pioneiro, mostraram como estimar o $\mathrm{pH}$ de reações orgânicas para atingir a máxima eficiência de obtenção de 
Tabela 3. Limites de tolerância para exposição de solventes.

\begin{tabular}{lccc}
\hline Substância $(\mathrm{ppm})$ & NIOSH & OSHA & NR-15 \\
\hline Benzeno & $0.1^{\mathrm{a}}$ & $1^{\mathrm{a}}$ & $1^{\mathrm{b}}$ \\
ciclo-hexano & $300^{\mathrm{c}}$ & $300^{\mathrm{a}}$ & $235^{\mathrm{b}}$ \\
Clorofórmio & $2^{\mathrm{d}}$ & $50^{\mathrm{e}}$ & $20^{\mathrm{b}}$ \\
Diclorometano & $75^{\mathrm{c}}$ & $500^{\mathrm{a}}$ & $156^{\mathrm{b}}$ \\
\hline
\end{tabular}

Abreviaturas: NIOSH: National Institute for Occupational Safety and Health. OSHA: Occupational Safety and Health Administration. NR-15: Norma Regulamentadora número 15 do Ministério do Trabalho Brasileiro.

a- Limite de exposição para uma jornada de $8 \mathrm{~h}$ diárias. b- Limite de exposição para uma jornada de $48 \mathrm{~h}$ semanais. c- Limite de exposição para uma jornada de $10 \mathrm{~h}$ diárias. d- Limite de exposição recomendado para $60 \mathrm{~min}$.

e- Limite de exposição permitido como valor limite, não devendo ser ultrapassado em momento algum.

produto e também como controlar o $\mathrm{pH}$ para obter seletividade em dois sítios nucleofílicos diferentes; as reações estudadas foram acilação e sulfonação de aminas e alquilação de cetonas (Esquema 5). A escala usada foi de $\mathrm{mg}$ a algumas gramas ${ }^{18}$.
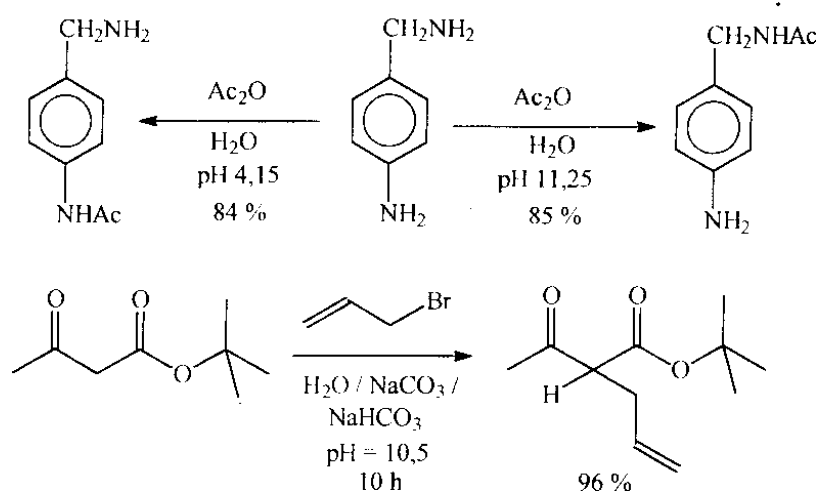

Esquema 5. Algumas reações orgânicas em água.

Em realidade, reações conduzidas em água são uma recente tendência em síntese orgânica tanto do ponto de vista industrial como acadêmico ${ }^{3,6,19,20}$. Reações tipo Barbier-Grignard ${ }^{19,20}$ já foram conduzidas em água ou em misturas de solventes com água, sendo que vantagens óbvias seriam a não necessidade de solventes anidros ou de manipular solventes inflamáveis, além de um grande ganho para o meio ambiente ${ }^{19,20}$. Uma outra vantagem apontada seria a não necessidade de proteção/ desproteção de certos grupamentos funcionais com hidrogênio ácido, que contribuiria para uma maior eficiência sintética ${ }^{20}$.

Um exemplo industrial importante da utilização de água como solvente é o processo bifásico da Rurchemie AG (agora Hoescht AG) / Rhône-Poulenc para a produção industrial de 1butanal, que segundo Cornils e Wiebus possui virtualmente nenhum impacto ambiental e que está em operação desde $1984^{21}$. O processo usa um catalisador solúvel em água a base de ródio (e que não é tóxico: $\mathrm{DL}_{50}=>5000 \mathrm{mg} / \mathrm{Kg}$ ) e a reação entre propeno e monóxido de carbono e hidrogênio com uma pressão de cerca de $50 \mathrm{~atm}$ (Esquema 6) ${ }^{21}$.

A produção do 1-butanal por este tecnologia é de 330.000 toneladas por ano. Este novo processo de hidroformilação possui diversas vantagens sobre o processo convencional que utiliza um catalisador a base de cobalto (carbonila de cobalto) e alta pressão ${ }^{21}$. Algumas destas vantagens que são relevantes para o meio ambiente são:

1 - uma geração de efluentes aquosos 70 vezes menor do que o processo convencional (catálise heterogênea e carbonila de cobalto como catalisador),

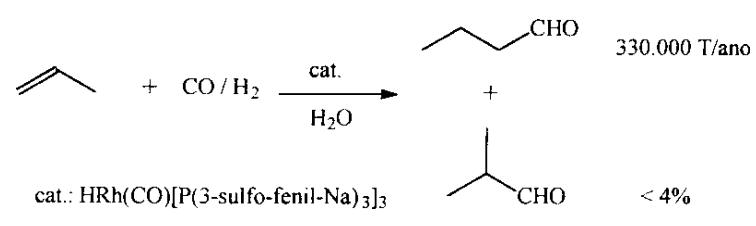

Esquema 6. Síntese industrial do l-butanal da Rhône-Poulenc.

2 - menor geração de subprodutos orgânicos em cerca de 6 vezes menos que o processo com a carbonila de cobalto, 3 - uma considerável menor razão de $\mathrm{Kg}$ de subprodutos (ou rejeitos) por $\mathrm{Kg}$ de 1-butanal $(<0,04)$ em relação ao processo tradicional $(>0,6)$.

Após a implantação deste processo em 1984 houve um grande aumento no estudo de catalisadores solúveis em água e suas aplicações ${ }^{22}$, e que permanece com grande interesse até hoje. Outros exemplos na indústria usando catalisadores solúveis em água em sistema bifásico para a formação da ligação carbonocarbono já foram relatados ${ }^{22}$. Uma nova síntese da vitamina A e E também da Rhône-Poulenc utiliza esta tecnologia recente ${ }^{23}$ com um catalisador solúvel em água.

\section{SOLVENTES SUPERCRÍTICOS}

Um gás é supercrítico quando sua temperatura e pressão ultrapassam seus valores críticos, embora na prática o termo é usualmente restrito a temperaturas não muito acima de $T_{\mathrm{c}}{ }^{24}$. A substância não condensa ou evapora, mas existe como um fluido. Este ponto para um componente puro é a maior temperatura na qual líquido e vapor podem existir na mesma temperatura. O valor destes fluidos supercríticos é que como possuem propriedades intermediárias entre gases e líquidos pode-se obter condições ótimas para processos e experimentos, através da variação da pressão ou temperatura. Outra grande vantagem são os benefícios ambientais que certos fluidos supercríticos podem trazer, já que dióxido de carbono $\left(\mathrm{scCO}_{2}, T_{\mathrm{c}}=31{ }^{0} \mathrm{C}\right.$ e $\left.p_{\mathrm{c}}=74 \mathrm{~atm}\right)$ e água $\left(\mathrm{scH}_{2} \mathrm{O}, T \mathrm{c}=374{ }^{0} \mathrm{C}\right.$ e $\left.p_{\mathrm{c}}=220 \mathrm{~atm}\right)$ são plenamente disponíveis como solventes ${ }^{24}$, além de serem baratos e, em geral, inertes. Além disso, dióxido de carbono pode ter sua polaridade aumentada pela adição de uma pequena quantidade de metanol, por exemplo, de forma que a mistura é ainda bem menos tóxica que muitos solventes orgânicos ${ }^{24 a}$. O caso da água é ainda mais interessante, pois em condições supercríticas a polaridade da água é menor do que em temperaturas mais baixas, o que é indicado pelo seu produto iônico que diminui em algumas ordens de magnitude ao ultrapassar-se $T_{\mathrm{c}} \mathrm{e}$ $p_{c}$, o que torna as substâncias orgânicas muito mais solúveis ${ }^{24 a}$. Uma desvantagem da água é que possui uma elevada temperatura e pressão crítica, quando comparada com $\mathrm{CO}_{2}$.

Em uma escala industrial o primeiro e mais famoso exemplo de utilização de fluido supercrítico é a descafeinação de grãos de café por dióxido de carbono supercrítico (processo de Hag). A utilização de $\mathrm{CO}_{2}$ supercrítico para extração vem sido surpreendentemente explorada em grande escala pela indústria de alimentos e perfumes ${ }^{24 a}$, devido a necessidade da ausência de resíduos tóxicos ou substituição de solventes que danificam a camada de ozônio.

Uma grande tendência atual é também o estudo de reações químicas em fluidos supercríticos, onde a utilização de solventes como o dióxido de carbono seria de grande vantagem ambiental. Um exemplo importante de como esta tecnologia já estaria sendo incorporada na indústria seria a produção de 2butanol pela companhia Idemtsu Petrochemical, no Japão, pela reação catalisada de água e buteno supercrítico, sendo que foi relatado que esta planta estaria em operação em uma escala de milhares de toneladas por ano ${ }^{24 b}$ (Equação 3).

Um outro exemplo interessante é a hidrogenação catalítica de precursores de vitaminas usando $\mathrm{CO}_{2}$ supercrítico/ $\mathrm{H}_{2}$ da Hoffman 
Equação 3. Produção do 2-butanol com 1-buteno supercrítico.

La Roche, onde é conhecido que um reator de batelada de 10.000 L do processo convencional foi substituído por um reator contínuo de apenas $40 \mathrm{~L}$ com uma produção de $800 \mathrm{t}$ por ano ${ }^{24 b}$. Outro fato que merece destaque é que $\mathrm{o}_{2}$ é muito mais solúvel no fluido supercrítico do que em solventes orgânicos, sendo esta uma grande vantagem para estes processos de hidrogenação.

\section{SOLVENTES PERFLUORADOS}

A utilização de solventes perfluorados em substituição a solventes clorados para reações orgânicas tem sido muito estudada nos últimos anos, sendo uma recente tendência em síntese orgânica ${ }^{25}$. Reações de esterificação já foram conduzidas de forma eficiente e em uma escala de dezenas de gramas em solvente perfluorado ${ }^{25 a}$. Estes solventes perfluorados teriam diversas vantagens em relação a solventes clorados: bem menor volatilidade, maior estabilidade, menos tóxicos ao homem e que não atacariam a camada de ozônio ${ }^{25}$. No entanto, já foi relatada há pouco tempo uma opinião totalmente desfavorável à utilização de solventes perfluorados: estes seriam tão estáveis que teriam um tempo de vida de 2.600 a 9.000 anos e que seriam possíveis gases de estufa, com um potencial milhares de vezes maior que o dióxido de carbono ${ }^{26}$. Alguns solventes perfluorados são mostrados na Tabela $4^{25 a}$.

Tabela 4. Alguns solventes perfluorados.

\begin{tabular}{lccc}
\hline $\begin{array}{l}\text { Solvente } \\
\text { Perfluorado }\end{array}$ & $\begin{array}{c}\text { P. e. } \\
\left({ }^{\circ} \mathrm{C}\right)\end{array}$ & $\begin{array}{c}\text { Densidade } \\
\left(\text { a } 25^{\circ} \mathrm{C}\right)\end{array}$ & $\begin{array}{c}\text { Solubilidade em } \\
\text { água }(\mathrm{ppm})\end{array}$ \\
\hline $\mathrm{C}_{6} \mathrm{~F}_{14}$ & 57,0 & 1,68 & 10 \\
$\mathrm{C}_{7} \mathrm{~F}_{16}$ & 82,5 & 1,73 & 11 \\
$\left(\mathrm{C}_{4} \mathrm{~F}_{9}\right)_{3} \mathrm{~N}$ & 173,4 & 1,88 & 7.0 \\
\hline
\end{tabular}

\section{REAÇÕES NO ESTADO SÓLIDO E REAÇÕES SEM SOLVENTE}

A ausência de solvente em reações orgânicas é uma recente tendência em síntese, sendo que em muitos casos são obtidos rendimentos maiores e uma maior seletividade do que quando a mesma reação é realizada com solvente ${ }^{27}$, e uma das azões é que as moléculas em um cristal estão arranjadas de forma regular e mais juntas do que na reação em solução. Há também a possibilidade de reações sólido-sólido enantiosseletivas ${ }^{27}$. A reação no estado sólido é geralmente conduzida misturando-se os reagentes em pó finamente dividido à temperatura ambiente, onde também estas reações são aceleradas por aquecimento, agitação, ultra-som ou, simplesmente, com maceração em um gral com pistilo ${ }^{27 a}$. Uma aplicação muito interessante é a transferência de metileno para ligações duplas $(\mathrm{C}=\mathrm{C}, \mathrm{C}=\mathrm{O}$ e $\mathrm{C}=\mathrm{N})$ visando a formação de ciclopropanos, epóxidos e aziridinas, que segundo $\operatorname{Toda}^{28}$ seria uma forma mais simples e eficiente de realizar esta reação do que o procedimento em solução (Equação 4).<smiles>C=C(C=Cc1ccccc1)c1ccccc1</smiles><smiles>CCOC(C)=O</smiles>
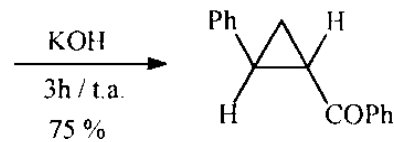

Equação 4. Transferência de metileno no estado sólido.

Uma revisão sobre síntese orgânica em ausência de solvente foi recentemente publicada por Metzger ${ }^{29}$. O trabalho relata reações sem solvente para o caso específico onde pelo menos um dos reagentes é um líquido nas condições usadas, e foram apresentadas reações em escala de laboratório e escala industrial $^{29}$. Um exemplo importante do último caso seria um novo processo mais ameno para o meio ambiente desenvolvido pela Hoechst para a obtenção do polipropileno em ausência de solvente, sendo que o método clássico para a manufatura deste polímero é através do processo Ziegler-Natta, com a polimerização em um solvente relativamente volátil (como uma fração leve do petróleo), onde a questão da separação e secagem do polímero tornavam difícil a recuperação do solvente, ocorrendo perdas para o meio ambiente ${ }^{29}$.

Um exemplo recente de como esta técnica é útil foi relatado por pesquisadores iranianos, onde a reação de Friedel-Crafts de acilação e alquilação foi conduzida sem solvente, simplesmente misturando os reagentes em um gral por tempos reacionais, geralmente, curtos (por exemplo: $45 \mathrm{~min}$ ) e depois procedendo ao isolamento. Em muitos casos foram obtidos altos rendimentos. Além disso, a reação de benzeno ou tolueno com brometo de isopropila teria fornecido produtos inesperados para a surpresa destes cientistas, com substituição do anel aromático em posição meta ${ }^{30}$ (Esquema 7).
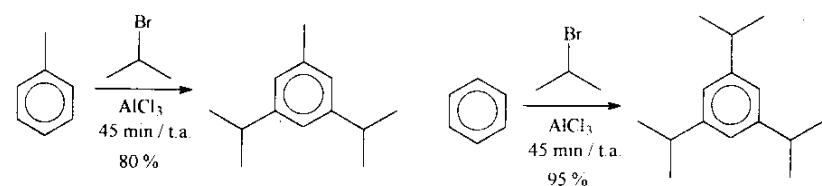

Esquema 7. Reações de alquilação de Fridel-Crafts em ausência de solvente

Uma outra técnica que vem crescendo muito nos últimos anos sendo alvo de enorme número de publicações é a condução de reações em ausência de solvente com irradiação por microondas ${ }^{31}$. As reações podem ser conduzidas tanto em um forno de microondas de cozinha quanto em reatores de microondas desenhados especificamente para reações orgânicas em escala de laboratório, onde o aquecimento por microondas teria vantagens sobre o aquecimento convencional (bico de bunsen, placa de aquecimento, manta) como maiores rendimentos, menor formação de subprodutos e tempo reacionais bem menores quando comparados ao aquecimento convencional. A utilização de aquecimento por microondas em reações químicas (sejam em ausência de solvente ou não) numa escala industrial tem despertado grande interesse de muitas companhias ${ }^{32}$, sendo que foi relatado a existência de uma planta de cloração de metano com irradiação por microondas da Dow Elanco ${ }^{32 a}$.

\section{CONCLUSÕES}

Os conceitos e aspectos apresentados sobre síntese orgânica limpa significam um melhor aproveitamento de recursos naturais e uma menor poluição para o meio ambiente. A filosofia de síntese limpa é uma realidade que vem gradualmente sendo executada no meio acadêmico e industrial. $\mathrm{O}$ conceito de economia atômica começa lentamente a ser incorporado pelos químicos orgânicos sintéticos tanto da indústria quanto da universidade, sendo que um desafio atual é a viabilização da aplicação deste conceito em processos industriais através de novas rotas e tecnologias mais eficientes. Recentes tendências como reações em água, reações sem solvente, utilização de microondas em síntese orgânica e o uso de dióxido de carbono supercrítico como meio reacional são uma realidade como linhas de pesquisa em laboratórios e alguns exemplos já começaram a aparecer na indústria. 


\section{AGRADECIMENTOS}

$\mathrm{O}$ autor agradece ao $\mathrm{CNPq}$ pela bolsa de doutorado, a Flavia Martins da Silva (IQ/UFRJ) e ao Prof. Marcio C. S. de Mattos (IQ/UFRJ) por discussões e sugestões úteis feitas a este trabalho, e ao Prof. David Ernest Nicodem (IQ/UFRJ) por discussões na disciplina Química do Meio Ambiente (IQ/UFRJ).

\section{REFERENCIAS}

1. Torres, E. M. M.; Revista de Química Industrial 1996, $64,12$.

2. Cascio, J.; Shideler, J. C.; Chemtech 1998, $28,49$.

3. Lester, T.; Chem. Brit. 1996, 32(12), 45.

4. a. Wilkinson, S. L.; Chem. Eng. News 1997, 75, 35. b. Clark, J.; Chem. Brit. 1998, 34(10), 43 (out.).

5. Hanson, D. J.; Chem. Eng. News 1998, 76, 19.

6. Laird, T.; Chem. Brit. 1996, 32(8), 43.

7. a- Sheldon, R. A. Chem. Ind. 1992, 23, 903. b- Sheldon, R. A. Chemtech 1994, 24, 38.

8. Aresta, M.; Quaranta, E. Chemtech 1997, 27, 32.

9. Trost, B. M.; Science 1991, 254, 1471.

10. March, J. M.; Advanced Organic Chemistry: Reactions, Mechanisms and Structure; John Wiley and Sons, Nova York, 1992; p. 956.

11. Raber, L. R.; Chem. Eng. News. 1998, 76, 25.

12. Horsley, J. A.; Chemtech 1997, 27, 45.

13. http://www.albrigth-wilson.com/whatsnew/6_24release.html.

14. Wilson, E.; Chem. Eng. News 1997, 75, 7.

15. Kakabase, G.; Solvent Problems in Industry; Elsivier, Londres, 1984; 253p.

16. a- $\mathrm{CHCl}_{3}$ e ciclo-hexano: http://www.osha-slc.gov/SLTC/ healthguidelines/index.html. b- benzeno: http://www.
osha-slc.gov:80/SLTC/contents.html. c- $\mathrm{CH}_{2} \mathrm{Cl}_{2}$ : http:// www. cdc.gov/niosh/86114_46.html. d- Hanson, D. Chem. Eng. News 1997, 75, 7.

17. http://www.mtb.gov.br/legi/nrs/nr15q.htm.

18. King, J. F.; Rathore, R; Lam, J. Y. L.; Guo, Z. R.; Klassen, D. F.; J. Am. Chem. Soc. 1992, 114, 3028.

19. Lubineau, A.; Augé, J.; Queneau, Y.; Synthesis 1994, 741. 20. Li, C. -J.; Tetrahedron 1996, 52, 5643.

21. Cornils, B.; Wiebus, E.; Recl. Trav. Chim. Pays-Bas 1996, $115,211$.

22. Herrmann, W. A.; Kohlpaintner, C. W.; Angew. Chem. Int. Ed. Engl. 1993, 32, 1524.

23. Mercier, C.; Chabardes, P.; Pure \& Appl. Chem. 1994, 66, 1509.

24. a- Clifford, T.; Bartle, K.; Chem. Brit. 1993, 29, 499. bPoliakoff, M.; Howdle, S.; Chem. Brit. 1995, 31, 118.

25. a- Zhu, D.- W.; Synthesis 1993, 953. b- Pereira, S. M.; Savage, G. P.; Simpson, G. W.; Synth. Commun. 1995, 25, 1023. c- Pozzi, G.; Montanari, F.; Rispens, M. T. Synth. Commun. 1997, 27, 447.

26. Warhurst, M.; Chem. Brit. 1997, 33, 22.

27. a-Toda, F.; Acc. Chem. Res. 1995, 28, 480. b- Singh, N. B.; Singh, R. J.; Singh, N. P. Tetrahedron 1994, 50, 6441.

28. Toda, F.; Imai, N.; J. Chem. Soc., Perkin Trans. 1 1994, 2673.

29. Metzer, J. O.; Angew. Chem. Int. Ed. 1998, 37, 2975.

30. Ghiaci, M.; Asghari, J.; Synth. Commun. 1998, 28, 2213.

31. a- Caddick, S.; Tetrahedron 1995, 51, 10403. b- Mingos, D. M. P.; Baghurst, D. R.; Chem. Soc. Rev. 1991, $20,1$. c- Loupy, A.; Petit, A.; Hamelin, J.; Texier-Boullet, F.; Jacquault, P.; Mathé, D.; Synthesis 1998, 1213.

32. a- Stinson, S.; Chem. Eng. News 1996, 74, 45. b- Dagani, R.; Chem. Eng. News 1997, 75, 26. 